\title{
A point to consider in the statistical analysis of scientific studies
}

\author{
Mehmet Kalayci, (1) Hatice Kalayci
}

Department of Medical Biochemistry, Elazig Fethi Sekin City Hospital, Elazig, Turkey

\section{Dear Editor,}

We read the article "Reduced ferritin, folate, and vitamin B12 levels in female patients diagnosed with telogen effluvium" by Ertug et al. with great interest [1]. We congratulate the authors for this valuable contribution. We would like to add a brief note to help readers interpret the results of the study.

In scientific studies, one of the most important aspects of statistical analysis is the distribution of data. To be able to perform parametric tests, the data should first be normally distributed. Unless the data analysis indicates a normal distribution, these variables should not be analyzed using standard parametric tests, such as t-tests and analysis of variance. Non-parametric tests (e.g., Mann-Whitney U test, Wilcoxon test, Kruskal-Wallis test) should be used for these variables [2].

The authors of this article explained the statistical analysis in detail in the Materials and Methods section. Using the ShapiroWilk test, the authors found that the data was not normally distributed, and as a result, the Mann-Whitney $U$ test, which is a non-parametric test, was used in intergroup comparisons [1]. Data analyzed using non-parametric statistics should be reported in tables or shown as median figures with an appropriate range (e.g., median, minimum and maximum values). Presenting variables that do not show normal distribution as mean \pm standard deviation can lead to the misinterpretation of the data [3]. In the Results section of the study, the ferritin and folate levels in the TE group are given in Table 1 as $17.35 \pm 18.54$ $\mathrm{ng} / \mathrm{mL}$ and $7.94 \pm 8.98 \mathrm{ng} / \mathrm{mL}$, respectively (as mean $\pm \mathrm{SD}$ ). Presenting the results in this way can lead to the misinterpretation that some of the results were below the minimum detection limit (e.g., folate: $-1.04-16.92 \mathrm{ng} / \mathrm{mL}$ ).

Mean and standard deviation (or standard error) values are not suitable for reporting data analyzed using non-parametric statistics. If the distribution of the data is not sufficiently normal and requires a non-parametric analysis, mean and standard deviation will not accurately represent the location and range of the data. When data are analyzed using nonparametric methods, such as the Mann-Whitney $U$ test, it is generally more appropriate to report median values with the minimum and maximum values, the $25^{\text {th }}$ and $75^{\text {th }}$ percentile values, or other central intervals [median (min-max)] [3].

Recognizing and understanding these errors will help researchers select the appropriate statistical methods and use them correctly, thereby improving the quality of their published study.

\section{References}

1. Ertug EY, Yilmaz RA. Reduced ferritin, folate, and vitamin B12 levels in female patients diagnosed with telogen effluvium. Int J Med Biochem 2018;1:111-4.

2. Ozdemir O. Medikal istatistik. 1st ed. İstanbul: İstanbul Medikal Yayıncilık; 2006.

3. Olsen $\mathrm{CH}$. Review of the use of statistics in infection and immunity. Infect Immun 2003;71:6689-92.

Address for correspondence: Mehmet Kalayci, MD. Department of Medical Biochemistry, Elazig Fethi Sekin City Hospital, Elazig, Turkey Phone: +90 5541182255 E-mail: dr_mehmetkalayci@msn.com ORCID: 0000-0001-9122-9289

Submitted Date: September 20, 2019 Accepted Date: October 21, 2019 Available Online Date: January 28,2020

${ }^{\circ}$ Copyright 2020 by International Journal of Medical Biochemistry - Available online at www.internationalbiochemistry.com OPEN ACCESS This work is licensed under a Creative Commons Attribution-NonCommercial 4.0 International License. 